\title{
Soil moisture: a residual problem underlying AGCMs
}

\author{
Adam R. Cornwell • L. D. Danny Harvey
}

Received: 19 August 2005 / Accepted: 13 March 2007 / Published online: 28 July 2007

(C) Springer Science + Business Media B.V. 2007

\begin{abstract}
This paper critically reviews and intercompares land surface schemes (LSSs) as used in atmospheric general circulation models (AGCMs) to simulate soil moisture and its response to a warmer climate, and potential evapotranspiration approaches as used in operational soil moisture monitoring and in predicting the response of soil moisture to a warmer climate. AGCM predictions of overall soil moisture change are in broad agreement but disagree sharply in some regions. Intercomparison projects have sought to evaluate the LSSs used by AGCMs for both accuracy and consistency. These studies have found that different LSSs can produce very different simulations even when supplied with identical atmospheric forcing. As well, LSSs that produce similar surface results from present-day or control climates often diverge when forced with climatic change data. Furthermore, no single LSS has been identified that produces an adequate simulation of all of temperature, moisture, evapotranspiration and runoff. AGCM LSSs must resolve the surface energy balance (SEB) in order to compute realistic heat fluxes between with the atmospheric model. LSSs have been used with AGCMs in both on-line (fully coupled) and off-line modes. In off-line climatic change experiments, AGCM predictions of atmospheric temperature and precipitation have been used, along with model downward radiative fluxes at the surface, to drive their own uncoupled LSS. However, there are simple nonenergy-balance methods for estimating evapotranspiration that have been traditionally used in agricultural and meteorological applications. These schemes compute a potential evapotranspiration (PE) based on temperature and/or net radiation inputs, with the $\mathrm{PE}$ modified based on the availability of soil moisture. Operational PE approaches have also been used with AGCM data in off-line climate change experiments. The advantages of this approach are that it is simpler and requires less information, although (like the off-line SEB approach) it leaves out the simulation of feedbacks between the surface and the atmosphere. Although the SEB approach is essential for LSSs that must be coupled to AGCMs, this does not necessarily make it superior to an off-line operational PE LSS when it comes to
\end{abstract}

A. R. Cornwell $(\bowtie) \cdot$ L. D. D. Harvey

Department of Geography, University of Toronto, 100 St. George Street, Toronto, ON M5S 3G3, Canada e-mail: cornwella@geog.utoronto.ca 
quantities such as soil moisture. The quality of current observational data is insufficient to demonstrate that either approach is better than the other. Both approaches should continue to be used and intercompared when predicting the impacts of climatic change on soil moisture.

\section{Introduction}

Changes in soil moisture will play a major role in the impacts of climatic change on agricultural production and on natural ecosystems (Robock et al. 1995; Gregory et al. 1997). Soil moisture deficits restrict plant respiration and reduce productivity. Extremely high or low soil moisture levels can lead to flooding or drought, and dry soil extends the length of heat waves (Brabson et al. 2005), all of which can have disastrous effects on crop yields.

The best available tool for predicting climatic change is the atmosphere-ocean general circulation model (AOGCM) (Kattenberg et al. 1996; Mearns et al. 2001). The atmospheric component of an AOGCM (the atmospheric GCM or AGCM) is coupled to a land-surface scheme (LSS) and used to predict changes in soil moisture. However, AGCM predictions of the magnitude and location of soil moisture changes often disagree and are often difficult to compare with one another (Houghton et al. 1996). The land surface schemes employed by the various AGCMs differ considerably, and their accuracy is questionable (Robock et al. 1998; Srinivasan et al. 2000); often the modellers' focus is on the surface energy balance, rather than the water budget (Schaake et al. 1996; Dirmeyer 2004). This presents a problem when assessing the impacts of climatic change on surface water supplies.

Robock et al. (1998) evaluated the present climate simulations of the 30 models that took part in the first Atmospheric Model Intercomparison Project (AMIP-I). They found significant differences in simulating soil moisture, particularly in the tropics, and overall excessive drying during the summer when compared to observations. A follow-up study by Srinivasan et al. (2000) examined the revised AMIP-I models, but did not find any systematic improvement in the results. Some of the discrepancies between models doubtlessly stem from disagreements in the various atmospheric models employed by the AGCMs; however, Bell et al. (2000) found that the structure of the LSS also leads to systematic differences in the AGCM simulations of surface temperature, precipitation, and soil moisture. Henderson-Sellers et al. (2003a) and Zhang (2004) identified the same pattern in the AGCMs of AMIP-II. Furthermore, the Project for Intercomparison of Land Surface Parameterizations (PILPS) found that no single LSS represented all of the important characteristics consistently (Henderson-Sellers et al. 1996). As well, a lack of quality observational data hinders attempts to evaluate LSS performance (HendersonSellers et al. 2002; Henderson-Sellers et al. 2003b; Varis et al. 2004).

This paper reviews the major findings of LSS intercomparison studies, with particular emphasis on the implications for simulating the impact on soil moisture of changes in climate. An alternative approach to modelling land surface climate change, using potential evapotranspiration methods, is also examined, and the relationships between the two approaches clarified. At issue is how much confidence should be placed in current predictions of future changes in soil moisture, and which approach is more reliable. We argue here that with our current observational limits neither method can be proven to be more reliable, and so predictions from either should be treated with equal merit. The use of 
alternative approaches, if they yield consistent results, will increase the credibility of predicted changes involving otherwise highly uncertain processes.

\section{A problem of definition}

One problem in discussing soil moisture modelling is that the quantity itself is often poorly defined. As noted above, from the standpoint of an AGCM, the latent heat flux and associated moisture transfer are the points of interest, and as long as the evapotranspiration is reasonable the change in the storage of water is of secondary importance (Schaake et al. 1996; Dirmeyer 2004). As a consequence, the definition and treatment of soil water varies from one model to the next.

Dirmeyer (2004) provides a useful overview of several of these treatments. He categorized the approaches taken by modellers as either a water mass approach ("soil moisture" measured in units such as $\mathrm{kg} \mathrm{m}^{-3}$ or millimetres) or a physical index approach ("soil wetness" given as the volume of water as a fraction of the pore volume). In either case, a further distinction can be made between the total amount of water in the soil and an amount referred to as the "plant available" soil water. The latter is delimited by the "wilting point" (the dry limit beyond which plant roots are no longer able to extract any of the remaining water) and the amount of water at saturation.

Given these varying definitions, and that evapotranspiration is the key AGCM quantity, it is tempting to focus on evapotranspiration for this review as well. Nevertheless, those AGCMs that close the surface water balance do necessarily claim to model soil moisture. Some expression of the total water available for evapotranspiration must be maintained. While soil moisture change may merely represent the residual of evapotranspiration and precipitation from the modelling perspective, it is of critical importance from the perspective of determining the impacts of climate change (global or local) (e.g. Brumbelow and Georgakakos 2001; Brabson et al. 2005). As well, the parameterizations of runoff also vary between AGCM LSSs, and this process is felt directly by the soil moisture variable. Leplastrier et al. (2002) note that focusing too much on reducing the errors in evapotranspiration (and runoff) in a LSS can actually increase the error in other quantities.

While evapotranspiration concerns dominate this review, it is our opinion that in order to get the full picture of uncertainties and inconsistencies between AGCM LSSs all of the factors that play a role in the LSS determination of soil moisture are important.

\section{Land surface modelling in AGCMs}

\subsection{Requirements and limitations}

Coupling land surface and atmosphere components together in an AGCM requires, at a minimum, modelling the energy transfer processes: exchanges of radiation, sensible and latent heat fluxes, friction between the air and surface (Sellers et al. 1997), and precipitation. In early AGCMs, sensible and latent heat fluxes were generally treated as quasi-diffusive processes using the method of Budyko (1956). Soil moisture storage was estimated using a simple "bucket" model (e.g. Manabe 1969), in which moisture storage occurs in a bucket of limited capacity. Precipitation fills the bucket, evapotranspiration takes water away, and any remainder beyond the bucket's capacity is lost as runoff. 
Stomatal resistance to evapotranspiration increases in response to decreases in available soil moisture, and also in response to increases in $\mathrm{CO}_{2}$ (Henderson-Sellers et al. 1995a; Lockwood 1999). More recent AGCMs therefore use a category of LSS called surfacevegetation-atmosphere transfer (SVAT) schemes, which include representations of the vegetation canopy and its roles in controlling evapotranspiration and intercepting precipitation (Henderson-Sellers et al. 2002). In these schemes, moisture and energy transfers within the soil are modelled using multiple soil layers; the top layer can interact directly with the atmosphere while water can filter down to lower layers and be brought back up through the root system (Sellers et al. 1997). Examples of SVATs include the Simple Biosphere Model ( $\mathrm{SiB}$ and SiB2) (Sellers et al. 1989; Sellers et al. 1996), the Biosphere-Atmosphere Transfer Scheme (BATS) (Dickinson et al. 1993), the Met Office Surface Exchange Scheme (MOSES) (Cox et al. 1999) and the Canadian Land Surface Scheme (CLASS) (Verseghy 1991; Verseghy et al. 1993).

At high latitudes or altitudes, LSSs must also deal with snow. Precipitation falling at temperatures below the freezing point typically falls as snow and accumulates on the surface. Some of this snow may melt during the course of temperature changes through the winter, but generally the majority of the snow cover melts during a relatively short time period in the spring, releasing large amounts of water. Much of this water runs off before it has time to infiltrate the soil; if the soil is still frozen when the ice melts, this may also inhibit the infiltration of meltwater (Pitman et al. 1999b). Snow cover also has a high albedo and acts as an insulator between the atmosphere and the land surface, greatly reducing heat and moisture transfers (Lynch-Stieglitz 1994).

Evapotranspiration has a strong influence on (and is influenced by) not only soil moisture, but also the overall climate simulated by AGCMs (Huang et al. 1996; Ducharne et al. 1998; Dirmeyer et al. 2000; Koster et al. 2004), so accurate calculations for this quantity are very important. Validation of the various LSSs is a difficult task, as there are very few long-term observations of quantities such as soil moisture storage or evapotranspiration. Those that do exist are generally limited in spatial scale and not necessarily of good quality (Roads et al. 1994; Henderson-Sellers et al. 2002). The Global Soil Wetness Project (GSWP) was founded to address this issue. The project is an attempt to combine what observations do exist with remote sensing techniques to eventually provide global data sets of land surface quantities and fluxes (Dirmeyer et al. 1999; Dirmeyer et al. 2002).

\subsection{AGCM LSS intercomparisons}

AGCM LSSs have been intercompared in a variety of ways, both in terms of their simulation of soil moisture for current climate conditions, and in terms of simulated changes in soil moisture under various global warming scenarios.

\subsubsection{Comparisons under present-day steady-state climates}

Many experiments have been conducted to compare the steady-state climates of LSSs. Polcher et al. (1996) compared three different AGCM LSSs using imposed atmospheric conditions in a set of 'off-line' (not coupled to an atmosphere AGCM) simulations. The authors found significant differences between the three schemes even when each was supplied the same atmospheric forcing. However, the authors were able to dramatically reduce the discrepancies by making adjustments that brought the surface resistance to evapotranspiration and soil moisture capacity of the three LSSs closer together. 
Chen et al. (1996) chose four very different LSSs and compared them with five months (May-October) of direct observations over a very small area. They found that while the quality of the simulations compared to observations did not necessarily depend on the complexity of the LSS, the two LSSs that did not explicitly account for changes in canopy resistance did not adequately represent evapotranspiration. In particular, they found that the Manabe (1969) bucket model systematically overestimated evapotranspiration from wet soils. This is consistent with other intercomparisons such as Bell et al. (2000) and Henderson-Sellers et al. (2003a).

Ducharne and Laval (2000) investigated the influence of the available soil moisture capacity in a coupled AGCM-LSS. They found that an increase in the moisture capacity led directly to an increase in the average annual evapotranspiration, and to regional precipitation increases in mid-latitude and decreases in the intertropical convergence zone. Rainbelts were particularly sensitive even to moisture capacity increases of only $10-20 \%$.

$\mathrm{Wu}$ and Dickinson (2005) compared AGCM-LSS modelled precipitation with observations from the Great Plains region of the US. In this study the model underestimated mean summer rainfall but overestimated the variability. The authors concluded that evaporation (as opposed to transpiration) was contributing excessively to precipitation variability.

The Project for Intercomparison of Land-Surface Parameterization Schemes (PILPS) is a project designed to improve land surface modelling through comparisons of the steady-state climates of many diverse AGCM LSSs (Henderson-Sellers et al. 1993; Henderson-Sellers et al. 1995b; Henderson-Sellers et al. 2002). There have been four phases in PILPS; the first two dealt with off-line experiments using atmospheric data prescribed either from a single AGCM or observational data sets (Shao and Henderson-Sellers 1996; Pitman et al. 1999a). The other two phases were on-line; the third phase compared LSS climates when coupled to their matching AGCM (Irannejad et al. 2001), and the fourth phase coupled several LSSs to a common AGCM (Zhang et al. 2001).

Tables 1, 2, 3, and 4 summarize the key findings of the PILPS project. Some features stand out from these analyses as being particularly important in differentiating LSSs. The soil moisture capacity is one quantity that is very important and yet often poorly addressed. Early LSSs used a uniform soil moisture capacity - typically $15 \mathrm{~cm}$ of equivalent water depth (Vinnikov and Yeserkepova 1991) - and this has been used even in some recent AGCM simulations (e.g. Emori et al. 1999; Boer et al. 2000). PILPS studies showed that

Table 1 Selected papers from PILPS phase 1: off-line tests with a common AGCM forcing

\begin{tabular}{ll}
\hline Authors & Key findings \\
\hline Pitman et al. 1993 & There is no consensus among LSSs on simulated evapotranspiration, runoff \\
& or snow cover \\
Pitman and Henderson- & There is agreement in annually averaged surface temperatures, but this \\
Sellers 1995 & is not apparent at diurnal or shorter timescales \\
Yang et al. 1995 & The spin-up time required by LSSs depends on their soil moisture \\
& storage capacity \\
Layers below the rooting zone are unimportant to the surface equilibrium & The most important features of a LSS are the partitioning of precipitation \\
Koster and Milly 1997 & into interception and throughfall, and partitioning soil moisture into \\
& evapotranspiration, runoff and continued storage \\
LSSs can be characterized by the efficiencies of evaporation and runoff \\
from unsaturated soils
\end{tabular}


Table 2 Selected papers from PILPS phase 2: off-line tests with observed forcing

Authors Key findings

Desborough et al. 1996

Divergence in the evaporation fluxes simulated by LSSs increased when temperature and soil moisture conditions were prescribed. This is due to the different formulations for bare soil evaporation; evaporation was more consistent when LSSs were allowed to simulate their own surface conditions Accurate simulations of evaporation and runoff can be achieved without an accurate value of the total soil moisture storage

Mahfouf et al. 1996

Disagreements during the growing season in LSS simulations come from: the initial soil moisture content; relationships between soil moisture levels and transpiration; and soil moisture capacity

Henderson-Sellers et al. 1996

No single LSS adequately simulates all of the important observed variables (soil temperature, soil moisture, evapotranspiration and runoff) satisfactorily or consistently

Shao and HendersonSellers 1996

Schemes with very different partitioning of runoff and evapotranspiration can have very similar soil moisture predictions

The choice of LSS physics may need to depend on the purpose of the LSS

Henderson-Sellers 1996 Observations of a few months or less cannot be used to validate LSSs because response times for some schemes are several months in length Soil moisture prediction is inconsistent and generally inaccurate

Chen et al. 1997

The quality of land surface observations is insufficient to identify some LSSs as being more accurate than others

Liang et al. 1998

LSSs with similar monthly mean heat fluxes can have quite different monthly standard deviations; therefore LSS intercomparisons should span multiple years

Pitman and Henderson- $\quad$ The scatter in evapotranspiration simulated by off-line LSSs is higher when Sellers 1998

Desborough 1999 the prescribed precipitation is lower

Most LSS disagreement at the daily level can be explained by two factors: surface complexity (multiple soil layers and vegetation canopy functions); off-line corrections to the turbulent transfer parameters in the atmosphere However, at monthly or larger timescales, a simple surface with constant evapotranspiration resistance is as good as a scheme with time-varying resistance

Leplastrier et al. $2002 \quad$ Additional surface energy balance complexity produces little improvement outside the calibration period

Evaporation and runoff may not be the best quantities for calibration

the soil moisture capacity is a key factor in the spin-up time of a LSS (Yang et al. 1995), in calculations of transpiration by a vegetation canopy (Mahfouf et al. 1996), and, most importantly, in the generation of surface runoff and subsurface drainage (Mahfouf et al. 1996; Desborough 1999).

Koster and Milly (1997) constructed a simple water balance model designed to replicate each of the off-line LSSs from the first phase of PILPS. Their model used a monthly time scale and was specifically calibrated for the tropical rainforest area of the PILPS experiment. They were successful in using this model to reproduce the annual cycle of evaporation of each of the 16 PILPS LSSs. After analyzing the sensitivity of the parameters and formulae of their simple model, they concluded that the most important features controlling the differences between the evaporation rates simulated by the PILPS LSSs were those determining the partitioning of throughfall into runoff and evapotranspiration, and those determining canopy interception. Of particular importance (as in Desborough 
Table 3 Selected papers from PILPS phase 3: on-line tests with native AGCMs

\begin{tabular}{|c|c|}
\hline Authors & Key findings \\
\hline $\begin{array}{l}\text { Henderson-Sellers } \\
\text { et al. } 1995 \mathrm{~b}\end{array}$ & $\begin{array}{l}\text { The differences in surface temperatures predicted by LSSs in Phase } 1 \text { and Phase } 2 \\
\text { were increased when coupled to their host AGCMs } \\
\text { Evapotranspiration depends on the availability of surface energy in wet areas, and } \\
\text { on precipitation in dry areas such as mid-latitudes }\end{array}$ \\
\hline Qu et al. 1998 & $\begin{array}{l}\text { The hypothesis that on-line feedbacks between LSS and AGCM dampen } \\
\text { land-surface differences is incorrect or at least unproven }\end{array}$ \\
\hline Robock et al. 1998 & $\begin{array}{l}\text { LSSs show excessive summer drying. Differences between models are particularly } \\
\text { evident in the tropics }\end{array}$ \\
\hline Irannejad et al. 2001 & $\begin{array}{l}\text { No model accurately captures both sensible and latent heat fluxes in all regions } \\
\text { or climates } \\
\text { LSSs agree best in very cold or very humid climates }\end{array}$ \\
\hline
\end{tabular}

et al. (1996)) were the runoff and evapotranspiration predicted by a given LSS when the soil moisture was less than capacity. Gedney et al. (2000) also characterized coupled LSSs from four AGCMs with a few general equations. They determined that the calculation of surface and subsurface runoff, again particularly at times when the soil was partially dry, was critical not only to steady-state climate simulations, but also in deciding the sensitivity of the LSS to climate change.

Leplastrier et al. (2002), Pitman et al. (2004) and Bagnoud et al. (2005) used modular LSSs to conduct off-line experiments using different levels of complexity to simulate the surface energy balance. They found no evidence that energy balance complexity had any systematic influence on air temperature variance. However, Pitman et al. (2004) also examined the results of AMIP-II and found that the more complex LSSs did simulate air temperature variances that were closer to observations. These studies support the conclusions of Koster and Milly (1997) and Gedney et al. (2000) that the surface hydrology dominates the LSS contributions to climate simulation.

PILPS studies found that the presence of a vegetation canopy in LSSs was important not only for estimating intercepted precipitation, but also for providing resistance to evapotranspiration from the soil (Mahfouf et al. 1996; Koster and Milly 1997; Desborough 1999). However, at time scales larger than 1 day, Desborough (1999) found that a calibrated surface resistance that was constant in time could work just as well. PILPS LSSs that did

Table 4 Selected papers from PILPS phase 4: on-line tests with a common AGCM

\begin{tabular}{ll}
\hline Authors & Key findings \\
\hline $\begin{array}{l}\text { Timbal and Henderson- } \\
\text { Sellers } 1998\end{array}$ & The choice of LSS has a significant impact on convective precipitation \\
Zhang et al. 2001 & in the AGCM \\
& LSSs that produce very similar evapotranspiration off-line can diverge when \\
coupled to the same AGCM \\
Menderson-Sellers \\
Many LSSs underestimate runoff, which causes them to overestimate \\
evapotranspiration \\
LSSs that do not include surface resistance to evapotranspiration perform \\
relatively poorly \\
Comparisons and assessments of LSSs are hampered by the lack of quality, \\
global-scale observations
\end{tabular}


not include some sort of surface resistance to evapotranspiration performed poorly (Henderson-Sellers et al. 2002).

The PILPS project also uncovered some fundamental uncertainties in AGCM approaches to modelling the land surface. PILPS authors repeatedly noted that none of the participating LSSs consistently captured all of the important land surface features to a reasonable degree of satisfaction (Henderson-Sellers et al. 1996; Irannejad et al. 2001). This is compounded by the lack of accurate, long-term and large-scale observations - often the estimated error bounds on the observations are of the same magnitude as the divergence in the LSS simulations (Henderson-Sellers et al. 2002).

Henderson-Sellers et al. (1995b) and Qu et al. (1998) reported that the divergence among LSSs increased when they were coupled to their home models in phase 3. Perhaps more importantly, Zhang et al. (2001) calibrated several versions of a LSS, of varying complexity, so that when forced with off-line observations the results of each version were similar. However, when the LSSs were coupled to an atmosphere model, the simulations of surface temperature and evapotranspiration diverged - the off-line agreement was not maintained.

The Global Land-Atmosphere Coupling Experiment (GLACE) is an ongoing intercomparison project that is investigating the strength of the influence of LSSs on AGCMs; for example, the question of to what extent soil moisture amount influences precipitation is under investigation (details at http://glace.gsfc.nasa.gov). Its pilot project, a four-model intercomparison, showed that this coupling strength varies significantly between models (Koster et al. 2002). A subsequent and larger (16-model) intercomparison identified regions where surface conditions had the strongest effects on precipitation (Koster et al. 2004). The authors determined that the model coupling was strongest in "transition zones" between wet and dry climates, where precipitation can be high but evaporation is still sensitive to soil moisture depletion. Both GLACE studies noted the dilemma that, while there is significant variability in the coupling strength among AGCM-LSSs, the real world coupling strength is not known.

\subsubsection{Comparisons of simulated changes in soil moisture}

Gedney et al. (2000) and Crossley et al. (2000) compared LSSs with and without a background climatic change. Both studies concluded that LSSs with similar stable climate simulations could have very different responses to simulated climatic change when coupled to AGCMs. Crossley et al. (2000) examined the effects of changing LSSs with four AGCMs. Each AGCM was coupled with two different versions of its own LSS (meaning eight different LSSs were available, but only the two versions of each AGCMs LSS could be used in any given model, since the LSSs were incompatible with each other). They examined the differences in the control hydrology using the different LSSs in each AOGCM, as well as the differences between different AGCMs (which are due both to the use of different AGCMs and different associated LSSs). They also ran $1 \times \mathrm{CO}_{2}$ and $2 \times \mathrm{CO}_{2}$ experiments, and examined the differences in the response of evaporation, precipitation, surface-air temperature, cloud cover, and net surface shortwave radiation at the surface to a doubling of $\mathrm{CO}_{2}$. The size of differences in the control climate between two different versions of an LSS, compared to the differences arising from using different AGCMs (and associated LSSs) depends on the variable being considered and the geographical location (especially latitude). However, the impact of differences in LSS, relative to the impact of differences in AGCMs, is generally greater when examining the climate response than in examining the control climate. They concluded that a change in LSS that has little effect on 
the control soil moisture budget of an AGCM can have a significant effect on the sensitivity of the soil moisture budget to a warmer climate, and vice versa.

Irannejad et al. (2003) developed pseudo-LSSs by using systems of linear equations to emulate the AGCM-LSSs of AMIP-II. The pseudo-LSSs were then run off-line with the atmospheric conditions from each of the other AMIP-II AGCMs. They concluded that the impact of changes to land surface parameterizations is dependent on the atmospheric conditions, and that this impact may change if the atmospheric conditions (i.e., climate) change.

As noted above, Phases 3 and 4 of PILPS showed that the difference between LSSs increases when they are coupled to atmospheric models (Henderson-Sellers et al. 1995b; Qu et al. 1998; Zhang et al. 2001), even in the absence of climatic change. The results of Gedney et al. (2000); Crossley et al. (2000) and Irannejad et al. (2003) suggest that introducing climatic change into the simulations can increase divergence even further. To the extent that soil moisture change has an important influence on climate, particularly precipitation (see Koster et al. 2004; Wu and Dickinson 2005), this casts doubt on the quality of AGCM predictions.

Variations in the temperature and precipitation changes provided by AGCMs to LSSs are of course another source of divergence in predicted changes in soil moisture. These differences are quantified and illustrated in Harvey (2004), and can be quite large in some regions, although for the latest generation of AGCMs there is better agreement than among previous AGCMs.

\section{Estimation of evapotranspiration from land surfaces}

Varis et al. (2004) provided a detailed overview of the challenges posed in applying climate model studies to water resources management. They stated that AOGCM output remains "crude and even inappropriate to watershed-scale hydrological analyses". From the foregoing discussion it can be seen that a number of problems and difficulties remain in the use of AGCM LSSs to predict changes in soil moisture in response to anticipated warming. It is appropriate, therefore, to briefly review the overall approach taken in AGCM LSSs - which is based on the surface energy balance - and to contrast this with the potential evapotranspiration (PE) approach, which is widely used in operational applications such as the prediction of irrigation requirements for crops, the prediction of crop yields, and the detection of emerging drought conditions.

We will work through a hierarchy of PE approaches, the first of which is most closely tied to the physics underlying the energy-balance approach of AGCM LSSs. Indeed, the evaporation computed in AGCM LSSs can be recast as a PE times a function that depends on the soil moisture, and the other components of the surface water balance - snowmelt, precipitation, and runoff - can be formulated in exactly or almost exactly the same way in operational schemes as in AGCMs. The difference between AGCM LSSs and operational $\mathrm{PE}$ schemes lies in the fact that an attempt is made to compute evaporation directly in terms of the driving physical forces in AGCMs, while in the operational PE scheme, PE is parameterized in terms of readily available input variables.

\subsection{Formulations used in AGCMs and in operational settings}

The land surface can be treated in a climate model as a thin slab with a finite (and non-zero) heat capacity, or it can be regarded as an infinitely thin interface (with zero heat capacity) 
between the atmosphere and the soil. In the first case, surface temperature is determined prognostically through an equation of the form

$$
R \frac{\mathrm{d} T_{s}}{\mathrm{~d} t}=Q^{*}-Q_{H}-Q_{E}
$$

where $R=c_{p} h$ is the "thermal inertia" $\left(\mathrm{J} \mathrm{m}^{-2} \mathrm{~K}^{-1}\right)$ of the surface slab of thickness $h, Q^{*}$ is the net surface radiation, $Q_{H}$ is the sensible heat flux, and $Q_{E}$ is the latent heat flux, equal to $L_{e} E$, where $L_{e}$ is the latent heat of evaporation and $E$ is evaporation flux. In the latter case, surface temperature is determined diagnostically by solving the equation,

$$
Q^{*}-Q_{H}-Q_{E}-Q_{G}=0
$$

where $Q_{G}$ is the heat flux into the soil. In most current models, a mixed prognosticdiagnostic approach is used. For example, the temperature of a surface soil slab and of canopy air can be determined prognostically, while the temperature of a zero-heat-capacity canopy foliage layer that is inserted between the soil and first model atmospheric layer can be determined diagnostically. In this case, separate sensible heat and moisture fluxes from the soil and the foliage to the canopy air, and from the canopy air to the free air above the canopy, are computed, as explained in Harvey (2000, Box 10.2).

In AGCMs, the sensible heat and evaporation fluxes are computed using the bulk aerodynamic or an equivalent approach, in which the driving forces are the surface-to-air temperature and humidity differences, respectively. That is,

$$
H=\rho c_{p} C_{D} U\left(T_{s}-T_{a}\right)
$$

and

$$
E=\rho C_{D} U\left(q_{s}-q_{a}\right) \beta=E_{p} \beta
$$

respectively, where $\rho$ is air density; $c_{p}$ is the specific heat of air; $C_{D}$ is a coefficient that depends on wind speed, atmospheric stability, and surface roughness; $U$ is the near-surface wind speed; $T_{s}$ and $T_{a}$ are the surface and air temperatures, respectively; $q_{s}$ and $q_{a}$ are the surface and air specific humidities, respectively; $E_{p}$ is potential evapotranspiration; and $\beta$ is a factor equal to 1.0 when the availability of soil moisture does not restrict evaporation and less than 1.0 when soil water is limiting. The surface specific humidity is computed as

$$
q_{s}=0.622 \frac{e_{s a t}\left(T_{s}\right)}{P_{a}}
$$

where $e_{\mathrm{sat}}\left(T_{s}\right)$ is the saturation vapour pressure evaluated at the surface temperature $T_{s}$. The term potential evapotranspiration was defined by Thornthwaite (1948) as the evapotranspiration from a vegetated surface when the supply of water is not limiting. Thus, the evaporation rate given by Eq. 4 can be thought of as a potential evaporation times a factor $(\beta)$ that reduces the evaporation by an amount depending on how dry the soil is. ${ }^{1}$

\footnotetext{
${ }^{1}$ The evaporation given by Eq. 4 with $\beta=1.0$ will be somewhat greater than the potential evapotranspiration as defined by Thornthwaite (1948), since, under water-limiting conditions (used in Eq. 4), the $T_{s}$ will be warmer than if water is plentiful (the condition to which Eq. 4 should be applied in order to compute $E_{p}$ ). This inconsistency has been discussed by Milly (1992), and is important if the formulation of $\beta$ as a function of soil moisture is meant to apply to the $E_{p}$ that would be computed using the temperature that would arise under conditions of plentiful moisture, rather than to the $E_{p}$ computed based on the actual surface temperature.
} 
The vapour pressure inside a leaf can be assumed to be at the saturation vapour pressure corresponding to the leaf temperature, so $e_{\text {sat }}\left(T_{s}\right)-e_{a}$ is indeed the correct driving force for evapotranspiration (as long as $T_{S}$ is the foliage temperature which, as noted above, is a predicted variable in most AGCMs). Actual evapotranspiration depends on the resistance to vapour flow from inside the leaf to the free air. Thus, an alternative to the bulk aerodynamic formulation is the resistance formulation of $Q_{H}$ and $Q_{E}$, given by

$$
H=\rho c_{p}\left(\frac{T_{s}-T_{a}}{r_{a}}\right)
$$

and

$$
E=\rho L_{e}\left(\frac{q_{s}\left(T_{s}\right)-q_{a}}{r_{a}+r_{s}}\right)=\frac{\rho c_{p}}{\gamma}\left(\frac{e_{\mathrm{sat}}\left(T_{s}\right)-e_{a}}{r_{a}+r_{s}}\right)
$$

respectively, where $r_{s}$ is the surface or stomatal resistance (governing vapor flow from inside the leaf, through the stomata to the surface of the leaf), $r_{a}$ is the aerodynamic resistance (governing the flow of both heat and moisture from the surface of the leaf to the surrounding air), and $\gamma=c_{p} P_{a} / 0.622 L_{e}$ is the psychrometric constant. The surface resistance $r_{s}$ depends on the stomatal opening, which in turn depends on soil moisture (in the most recent AGCMs, in which the coupled moisture and carbon fluxes are computed, $r_{s}$ also depends directly on the atmospheric $\mathrm{CO}_{2}$ concentration, or on the rate of photosynthesis as governed by soil moisture, temperature, atmospheric $\mathrm{CO}_{2}$, and the availability of photosynthetically-active radiation). Potential evapotranspiration can be defined as $E$ when $r_{s}=0$. Thus, Eq. 7 can be written as

$$
E=E_{p}\left(\frac{r_{a}}{r_{a}+r_{s}}\right)
$$

The computation of evaporation using Eqs. 4 or 7 requires a knowledge of the surface temperature, which is readily available in AGCM simulations. However, in the real world, $T_{a}$ can be easily measured but $T_{s}$ cannot be readily measured. This has led to the development of a number of operational formulations of evapotranspiration that can make use of readily available observations. Among the widely used formulations are those developed by Penman (1948) and further developed by Monteith (1965).

The surface saturation vapour pressure $e_{\text {sat }}\left(T_{s}\right)$ can be approximated in terms of the atmospheric saturation vapour pressure and the surface-air temperature difference using a first-order Taylor Series Expansion,

$$
e_{\mathrm{sat}}\left(T_{s}\right)=e_{\mathrm{sat}}\left(T_{a}\right)+\frac{\mathrm{d} e_{\mathrm{sat}}}{\mathrm{d} T}\left(T_{s}-T_{a}\right)
$$

Combining Eqs. 6, 7 and 9 with the surface energy balance given by Eq. 2, one obtains

$$
Q_{E}=\frac{\left(Q^{*}-Q_{G}\right) \Delta+\frac{\rho c_{p}}{r_{a}}\left(e_{\mathrm{sat}}\left(T_{a}\right)-e_{a}\right)}{\Delta+\gamma\left(1+\frac{r_{s}}{r_{a}}\right)}
$$

where $\Delta=\mathrm{d} e_{\mathrm{sat}} / \mathrm{d} T$. This is the Penman-Monteith equation or "combination model" for unsaturated surfaces. When $r_{s}=0$, Eq. 10 gives the Penman (1948) equation. It embodies the dependence of $Q_{H}$ and $Q_{E}$ on $T_{s}-T_{a}$ and $q_{s}-q_{a}$, respectively, as in the bulk aerodynamic equations used in climate models, but neither $T_{s}$ nor $q_{s}$ appear explicitly. 
The Penman-Monteith equation is generally interpreted as implying that evaporation is driven by two terms: the net radiation at the surface (minus the conductive heat flux into the ground, which can be estimated empirically), and the atmospheric vapour pressure deficit (VPD, $\left.e_{\mathrm{sat}}\left(T_{a}\right)-e_{a}\right)$. However, it is clear from the above derivation that the VPD is merely a proxy for the single physical driving term, $e_{\text {sat }}\left(T_{s}\right)-e_{a}$, and that the net radiation only indirectly drives evaporation, to the extent that it serves to maintain the surface temperature in the face of evaporative cooling. Thus, the Penman-Monteith equation is based on the same underlying physics as in AGCMs.

Under conditions of no water stress $\left(r_{s}=0\right)$, the Penman-Monteith equation can be rewritten as

$$
Q_{E}=\left(Q^{*}-Q_{G}\right)\left(\frac{\Delta}{\Delta+\gamma}\right)+\left(\frac{L_{e} \gamma}{\Delta+\gamma}\right)\left(\frac{e_{\mathrm{sat}}\left(T_{a}\right)-e_{a}}{r_{a}}\right)
$$

For a remarkably wide variety of land surfaces under well-watered conditions, the second term in Eq. 11 is $0.27-0.28$ times the first term. Thus, the latent heat flux during potential evapotranspiration is given by

$$
Q_{E}=1.27\left(Q^{*}-Q_{G}\right)\left(\frac{\Delta}{\Delta+\gamma}\right)
$$

This is the Priestley-Taylor Equation, originally derived empirically in a somewhat different way (Priestley and Taylor 1972).

A limitation in the use of the Penman-Monteith equation (or the empirical PriestleyTaylor equation) is that radiation data are not as widely available as surface-air temperature data. Thornthwaite (1948) developed an empirical formulation of $E_{p}$ that requires only screen-level air-temperature data as input:

$$
E_{p}=\left\{\begin{array}{l}
0, T_{a}<0^{\circ} \mathrm{C} \\
0.444 h\left(\frac{10 T_{a}}{I}\right)^{m}, 0 \leq T_{a}<26.5^{\circ} \mathrm{C} \\
-13.862+1.0747 T_{a}-0.01442 T_{a}^{2}, T_{a} \geq 26.5^{\circ} \mathrm{C}
\end{array}\right.
$$

where

$$
\begin{gathered}
m=\left(6.75 \times 10^{-7}\right) I^{3}-\left(7.71 \times 10^{-5}\right) I^{2}+\left(1.79 \times 10^{-2}\right) I+0.492, \\
I=\sum_{1}^{12} i, i=\left(\frac{T_{M}}{5}\right)^{1.514}, i \geq 0,
\end{gathered}
$$

$T_{M}$ is the climatological monthly average temperature, and $h$ is the hours of sunlight per day. Thornthwaite (1954) proposed using $\beta=w / w^{*}$, where $w$ is the soil water content (expressed as a depth of water) and $w^{*}$ is the soil-moisture holding capacity (assumed to be $10 \mathrm{~cm}$ everywhere). This computation of $E_{p}$ is combined with a simple formulation of runoff, and with data on monthly precipitation input, to compute changing end-of-month soil moisture amounts.

In summary, the evaporation computation in AGCMs and as used in operational settings involves, or can be formulated to involve, a potential evapotranspiration $\left(E_{p}\right)$ times a term that depends on the availability of soil moisture. The difference is in how $E_{p}$ is computed. 
In AGCMs, it is computed based on the physical driving term $\left(e_{\mathrm{sat}}\left(T_{s}\right)-e_{a}\right)$, while in operational applications, it is computed based on easily measurable quantities - either net radiation and surface air temperature (Penman-Monteith), net radiation alone (PriestleyTaylor), or air temperature alone (Thornthwaite). As air-temperature data are more readily available than radiation data, the Thornthwaite method is perhaps the most widely used operational method.

\subsection{Validation and use of the Thornthwaite method to compute $E_{p}$}

We now summarize studies that have (1) compared the soil water variation as computed with the Thornthwaite method against measured observations; (2) used the Thornthwaite method to develop evaporation and soil moisture climatologies or to analyze the variability of soil moisture and/or its relationship to temperature variability; and (3) used the Thornthwaite or related methods to project the impact on soil moisture of future greenhouse gas-induced warming.

\subsubsection{Validation of the Thornthwaite method}

Pelton et al. (1960), McGuiness and Bordne (1972) and Jensen (1973) presented relatively early evaluations of the Thornthwaite method. The latter two found the Thornthwaite evaporation to be consistently low compared to lysimeter-based estimates, but lysimeterbased estimates were known to be biased too high. Mintz and Serafini (1992) compared Thornthwaite, Penman-Monteith, and Budyko estimates of evaporation with measured evaporation at a site in Ohio. Their results are reproduced here in Fig. 1, where it can be seen that the Thornthwaite evaporation again seems to be too low. However, the shapes of the annual cycle using the three methods are similar, although the Thornthwaite cycle lags behind in the spring as a consequence of using temperature as a proxy for incident radiation. Huang et al. (1996) compared computed and measured soil moisture and runoff climatologies at sites in Illinois and Oklahoma, and some of their results are reproduced here in Fig. 2. There is good agreement between measured and calculated quantities.

Mintz and Walker (1993) used observed values of $Q^{*}$ and $T_{a}$ to compare the Thornthwaite and Priestley-Taylor equations at four locations. The results are presented here in Fig. 3 and show close agreement - within $\pm 0.5 \mathrm{~mm} /$ day - although the seasonal cycle demonstrates that Thornthwaite lags in springtime, as discussed above. They argue that because the Priestley-Taylor and Penman equations are approximately equal, the results of the Thornthwaite method are acceptably similar to both the Priestley-Taylor and Penman approaches.

Milly (1994a) estimated annual evaporation from observed precipitation and runoff in the central and eastern US. He found that this inferred evaporation was often in excess of the potential evaporation as predicted by the Thornthwaite method, and proceeded to scale the Thornthwaite $E_{p}$ by a factor 1.2 in a subsequent modelling effort (Milly 1994b).

Federer et al. (1996) intercompared seven methods for estimating $E_{p}$ at five climaticallydifferent locations. The methods included the Thornthwaite and Penman equations. While they found some large discrepancies in annual $E_{p}$ among the methods, there was overall agreement for a wide range of climates. They found that the Thornthwaite method is less error prone compared to other methods when long time steps are used, making it a better choice for use with monthly data.

A disadvantage of the Thornthwaite method is that it does not reflect the physical reality that evapotranspiration is governed by the surface humidity and (indirectly) by incident 

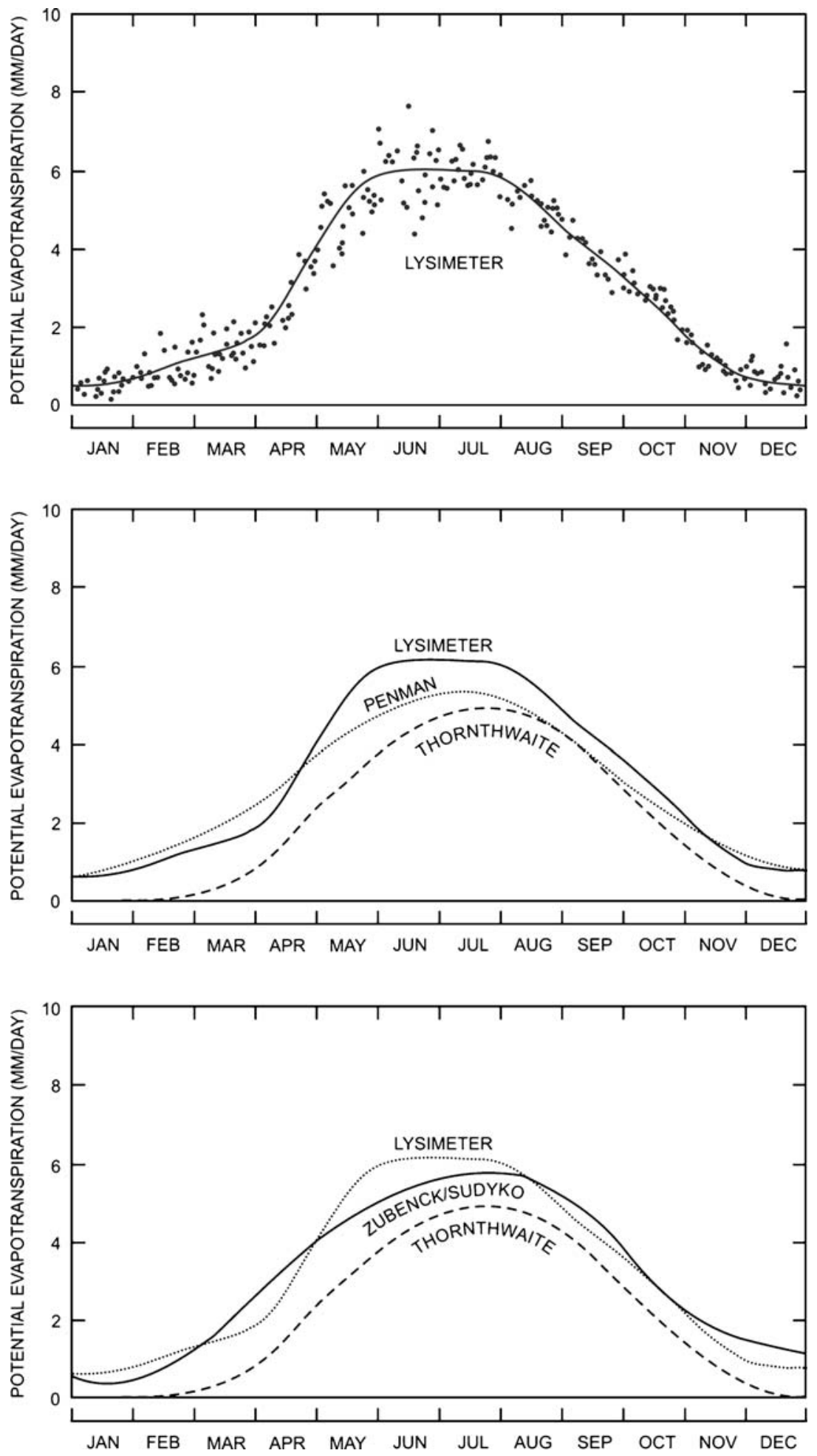
radiation (Durre et al. 2000). Instead, these processes are represented using the surface air temperature and solar declination (through the dependence of evapotranspiration on the number of hours of sunlight per day). This shortcoming may explain why Thornthwaite predictions lag behind other methods in the spring, when radiation increases faster than air temperature, and may also cause problems in cold or arid regions where real conditions are much different from the potential ones (Mintz and Serafini 1992; Federer et al. 1996).

\subsubsection{Water balance calculations}

The use of the Thornthwaite method in water-balance calculations goes back over 40 years. Mather (1962, 1963a,b,c, 1964a,b,c, 1965) computed monthly average potential evapotranspiration, evapotranspiration, runoff, and end-of-month soil moisture at several thousand stations around the world. Strahler and Strahler (1978, Fig. 10.11) produced maps based on the data tabulations of Mather for their classic physical geography textbook, Modern Physical Geography. Baumgartner and Reichel (1975, pp. 2-25 and Plates 5, 7, 10-14 and 17-20) produced maps of annual mean evapotranspiration. Willmott et al. (1981a,b) did water balance calculations using the Thornthwaite method for 13,332 stations with complete temperature and precipitation records. Mintz and Serafini (1984) produced global maps of evaporation and soil moisture using an alternative $\beta$ function,

$$
\beta=1-\exp \left(-6.8 \frac{w}{w^{*}}\right)
$$

and with a modified $w^{*}$ field. Willmott et al. (1985) adopted the above $\beta$ function and allowed for snow cover and snowmelt. They produced maps of monthly snow cover, soil moisture, and evaporation using monthly precipitation and temperature input data.

Mintz and Serafini (1992) allowed for partial interception of rainfall by vegetation. They computed daily $E_{p}$ values using daily $T_{a}$ data in Eq. 13 but monthly values in Eq. 15, with an appropriate alteration of the coefficients in Eq. 13. They produced monthly maps of potential evapotranspiration, evapotranspiration, soil moisture, and runoff. The latter allowed them to validate their calculations by comparison with observed runoff from large river basins. They found good agreement except at high latitudes, where the river flow was underestimated compared to the observations. This implies that the calculated runoff was too low, which may have been due to poor measurements or even systematic underestimation of snowfall.

Huang et al. (1996) used the Thornthwaite method to compute an historical (1931-1993) soil moisture dataset at 344 US climate stations, using monthly mean precipitation and temperature as inputs (however, they used a variable time step length in integrating the water balance equations). They examined spatial patterns, anomalies, and persistence of soil moisture variations. Finally, Nicholson et al. (1997) examined the soil water balance and its interannual variability at 1,400 rainfall stations in Africa with records generally in excess of 60 years in length. They relied largely on the Lettau (1969) "evapoclimatonomy" method, but did make some comparisons with the Thornthwaite and Penman-Monteith methods as benchmarks.

1 Fig. 1 Potential evapotranspiration at Coshocton, Ohio. Top: 15-year averages of daily $E_{p}$ as measured by deep-rooted grass lysimeters; Centre: $E_{p}$ as measured by lysimeters and as calculated with the Penman and Thornthwaite equations; Bottom: $E_{p}$ as measured by lysimeters, as calculated with the Thornthwaite equation, and as given by the Budyko equation (from Mintz and Serafini 1992, Fig. 5) 


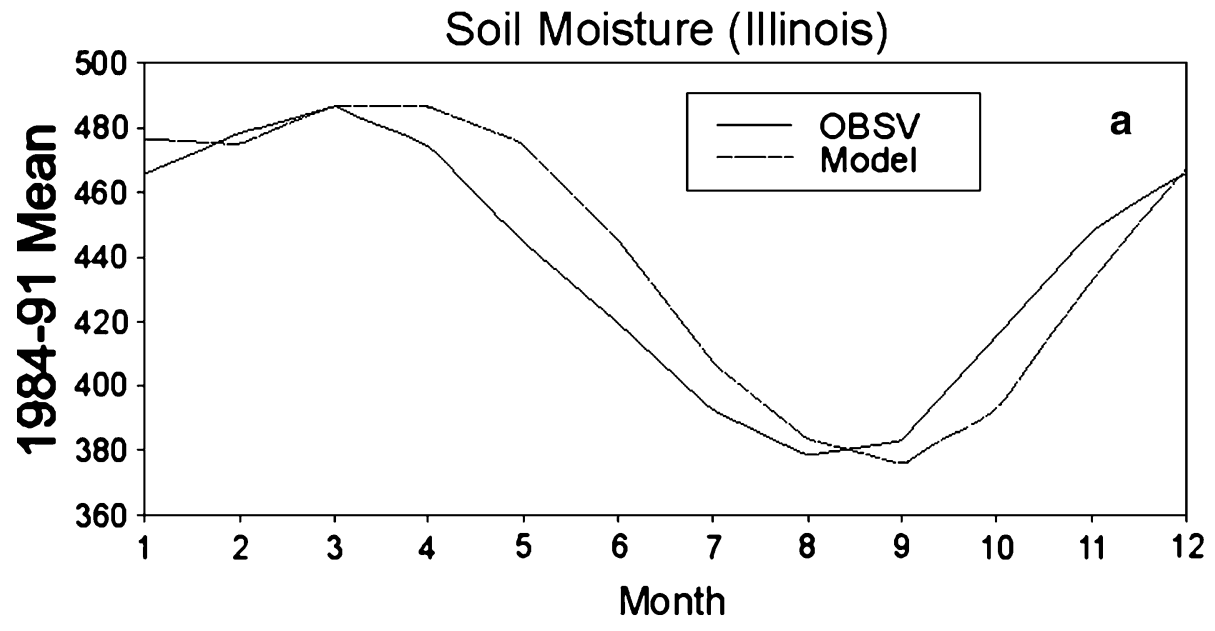

Soil Moisture (Illinois)
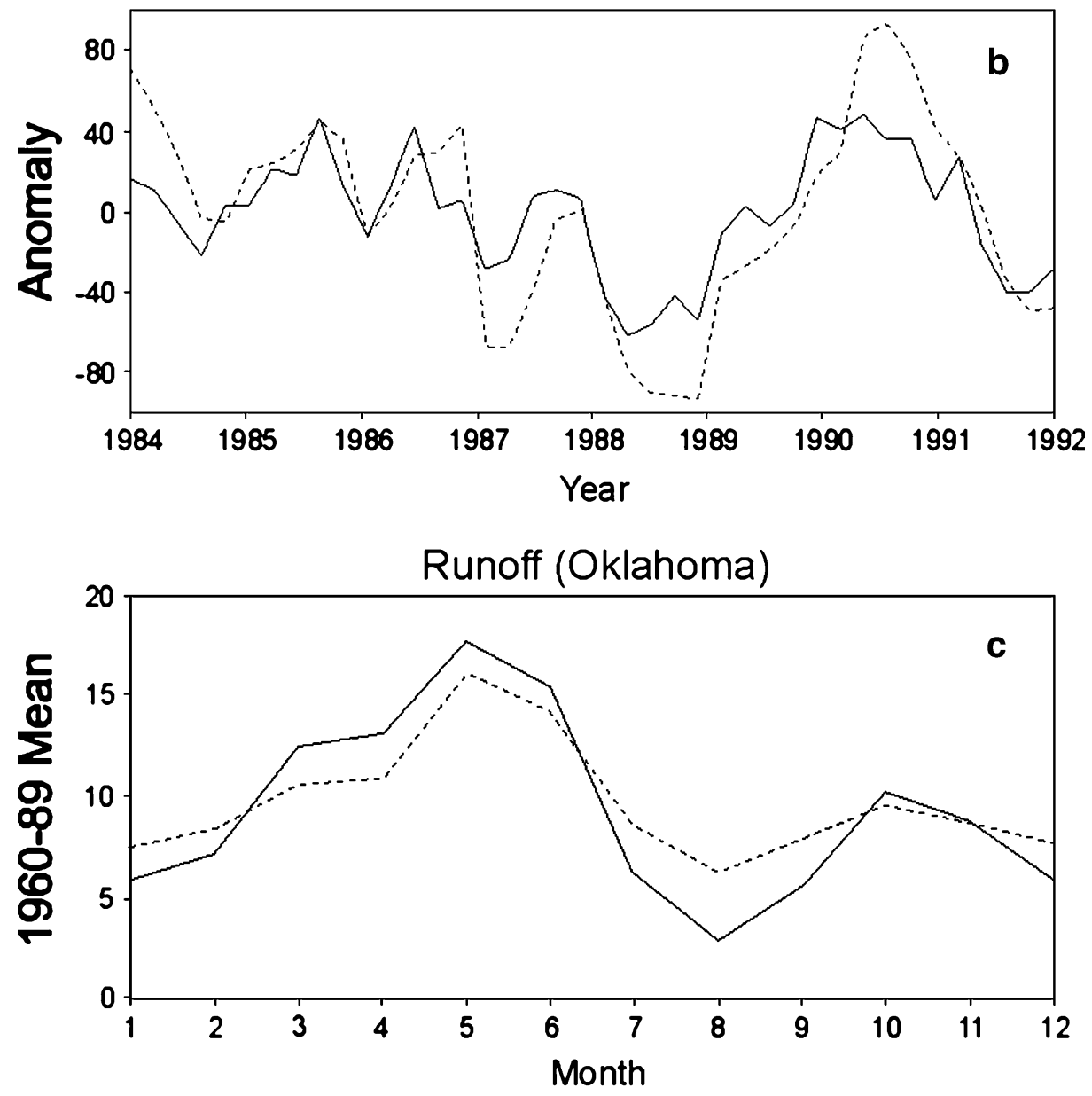
Fig. 2 Observed (solid line) and calculated (dashed line) values for: a monthly soil moisture (mm) averaged over 1984-1991; b soil moisture anomalies (mm) for May to September only; c runoff (mm) averaged over 1960-1989 (from Huang et al. 1996, Fig. 1)

\subsubsection{Seasonal drought monitoring and projected impacts of future warming}

The key advantage of the Thornthwaite method is that it requires only surface air temperature data. This makes it convenient for use in real-time detection of emerging drought conditions. The Thornthwaite equation is typically used in computing the Palmer Drought Severity Index (PDSI) (Palmer 1965). The PDSI is based on consecutive weeks or months of moisture deficit, determined by comparing precipitation with potential evapotranspiration under local climatic conditions. A detailed description of the implementation and limitations of the PDSI can be found in Alley (1984).

There are several contemporary examples of the use of the Thornthwaite equation and the PDSI. The US Weather Bureau (NOAA) and the US Department of Agriculture use the
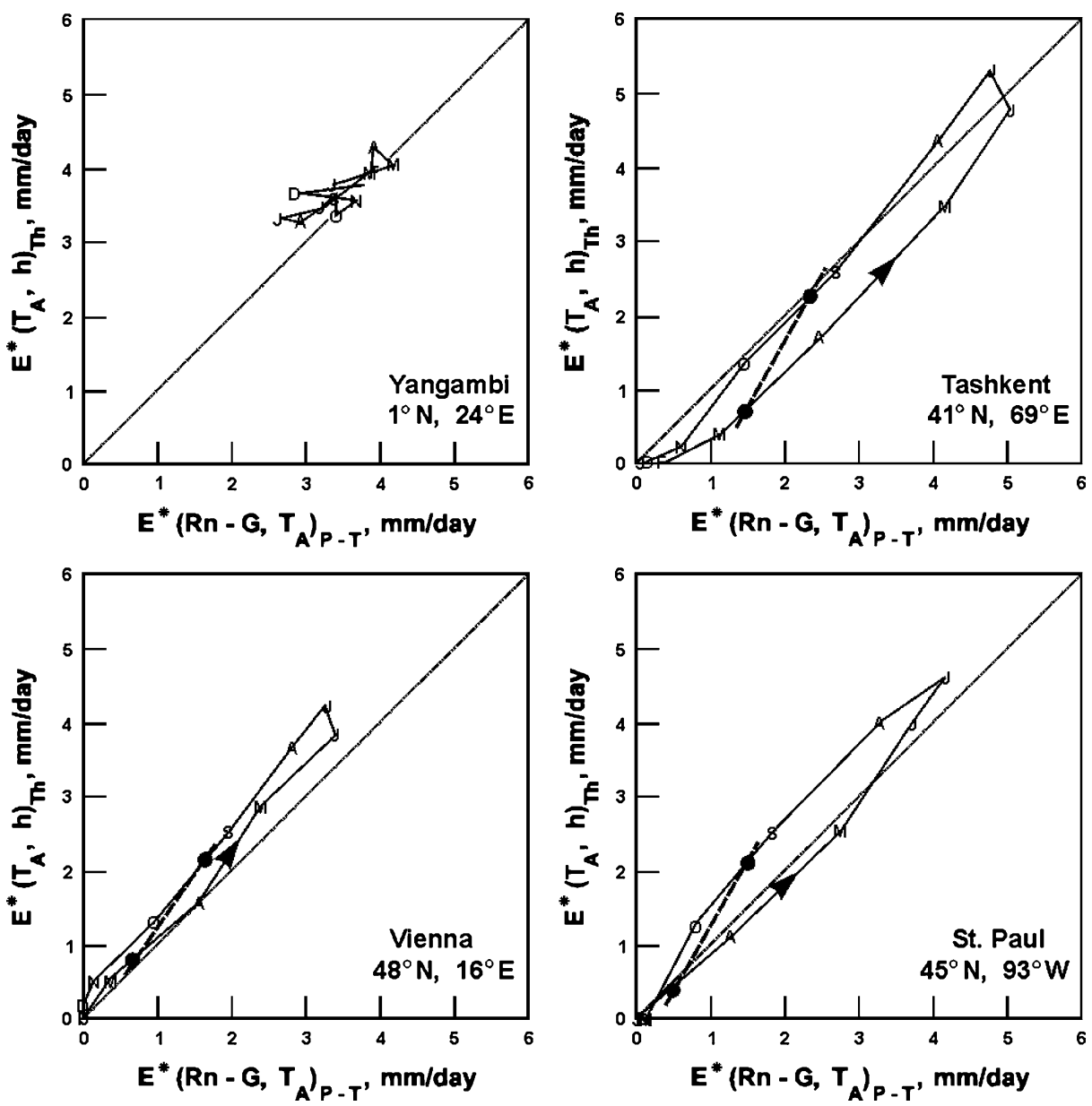

Fig. 3 Calculated $E_{p}$ following Thornthwaite (Th), compared with the calculated $E_{p}$ following Priestley and Taylor (P-T) (two circles indicate the spring and fall equinoxes) (from Mintz and Walker 1993, Fig. 9) 
Thornthwaite method to produce weekly and monthly PDSI and Crop Moisture Index Maps for the USA (in the Weekly Weather and Crop Bulletin available at http://www.usda. gov/agency/oce/waob/jawf/wwcb.html) (see Heim 2002). Atherton et al. (1998) describe the use of Thornthwaite's equation as part of a system to develop an official guide for agricultural water management for the state of Ohio. Waltman et al. (1997) made extensive use of the Thornthwaite equation in classifying soil moisture regimes across the state of Pennsylvania.

Given the widespread and successful use of the Thornthwaite and similar methods in operational applications, one might be tempted to use such methods with output from AGCMs in climate change simulations. However, the Thornthwaite method, and off-line models in general, have the disadvantage of lacking feedbacks in the exchanges of moisture and heat with the AGCM. In operational settings this does not matter, as observed atmospheric variables are continuously used to drive the soil moisture prediction scheme. In a coupled AGCM-LSS, latent and sensible heat fluxes from the LSS influence subsequent temperature and precipitation in the AGCM (Dirmeyer 2001; Wu and Dickinson 2005). However, if the strength of the coupling is weak, or if the fluxes that would be produced by the off-line LSS are relatively close to those of the on-line LSS, then the off-line model may still produce a realistic simulation of soil moisture. Off-line land surface modelling also has the advantage that smaller spatial scales can be used than those required by an AGCM.

In any case, a number of workers have used the Thornthwaite equation to assess the potential impact on soil moisture of future human-induced warming (Rind et al. 1990; Feddema and Mather 1992; Feddema 1999; Georgakakos and Smith 2001). Rind et al. (1990) argued that AGCM predictions of changes in soil moisture are unreliable, particularly since soils are often predicted to be so dry for the control climate that there is little room for further drying. They also argue that, even when the predicted changes in soil moisture are correct, such changes are not an adequate indication of future drought. Instead, they claim, drought depends on changes in $E_{p}$ rather than in $E$. Feddema (1999) made use of monthly temperature and precipitation changes from the HadCM2 model in on off-line calculation to project the impact on evaporation and soil moisture deficits in Africa due both to anticipated warming and to desertification (which is represented by reducing the soil-moisture-holding capacity). Feddema noted that similar increases in temperature would lead to much higher evapotranspirative losses in places where temperatures are already warm, such as in the tropics. Georgakakos and Smith (2001) estimated changes in soil moisture during the next century in the United States. They multiplied Thornthwaite's $E_{p}$ by a factor of 1.2, as recommended by Milly (1994a). They interpolated AGCM data from a Canadian Climate Centre AOGCM (CGCM1) to the specific locations of climate observation stations in the US. They predicted a definite drying trend - particularly in the southeastern US, which is consistent with predictions from CGCM1 (Boer et al. 2000).

\subsubsection{Climate change and the "pan paradox"}

As noted above, a disadvantage of the Thornthwaite method is that it does not directly consider changes in humidity or incident radiation. An example how this could become a problem is the phenomenon that has been referred to in the literature as the "pan paradox": despite the slight global warming observed over the past several decades, observations using open pans of water have shown a decrease in the rate of evaporation in many parts of the world over the same time span (Roderick and Farquhar 2002). Pan evaporation is used as an estimate of potential evapotranspiration, and would normally be expected to increase as the temperature rises. The cause of this reduction appears to be a combination of a 
decrease in incident radiation (due to solar radiation being reflected or scattered by aerosol pollution) (Nazarenko and Menon 2005) and an increase in relative humidity. The latter can occur due to increased precipitation in areas that had been moisture-limited; with more moisture available, the actual rate of evapotranspiration increases and decreases the vapour pressure deficit (Ramirez and Hobbins 2005).

The "pan paradox" presents a challenge to any LSS that does not consider changes in the surface radiation budget, but is particularly troublesome for the Thornthwaite method, which empirically treats insolation as a constant. Observations show that insolation decreased over the period 1960-1990, but that the trend has since reversed (Wild et al. 2005). Future changes in insolation depend on changes in pollution and on the effects that continued climate change may have on cloud cover, both of which are difficult to predict (Gifford et al. 2004). Empirical methods would only maintain their accuracy if the changes in insolation remained relatively small. To the extent that decreasing solar radiation and increasing cloudiness are due to aerosol pollution (Nazarenko and Menon 2005), and to the extent that aerosol emissions fall in spite of increasing $\mathrm{CO}_{2}$ emissions (or, even more so, decrease with decreasing $\mathrm{CO}_{2}$ emissions) (Smith et al. 2005), this will not be an issue in the long run.

\section{Conclusions}

AGCMs coupled to LSSs are most concerned with heat and energy fluxes; soil moisture is treated and even defined differently by different AGCM-LSSs. However, soil moisture is a critical quantity for assessing the impacts of climate change on natural systems, agriculture and water resources. While it is difficult to observe or simulate at the spatial scales used by AGCMs, it still deserves careful consideration.

Intercomparisons of the LSSs used by AGCMs have identified the most important factors in determining control-run soil moisture. These are the soil water-holding capacity, the inclusion of a canopy layer with a suitable stomatal resistance, the dependence of runoff on soil moisture, and the dependence of the evapotranspiration/potential evapotranspiration ratio on soil moisture. Together, these parameters determine the partitioning of rainfall into evaporation and runoff. Because of the predominant influence of a handful of simple parameters, LSSs can be calibrated to give similar soil moisture simulations in an off-line mode with a given fixed input forcing.

However, the results from Phases 3 and 4 of PILPS indicate that the difference between LSSs increases when they are coupled to atmospheric models (Henderson-Sellers et al. 1995b; Qu et al. 1998; Zhang et al. 2001). Other studies show that allowing for climatic change can further increase the divergence between LSSs even after getting as comparable a set of soil moisture simulations as possible for the present climate (Crossley et al. 2000; Gedney et al. 2000; Irannejad et al. 2003). While the quality of AGCM-LSSs appears to be improving (Henderson-Sellers et al. 2003a), without high-quality long-term observations and especially observations of the effects of changing climate - there remains significant uncertainty in AGCM predictions of soil moisture change.

On the other hand, operational schemes for simulating soil moisture changes and/or predicting drought conditions have been successfully used for many decades. These schemes make use of readily available observed data, and are ultimately derived from the same underlying physics as in AGCM LSSs. However, they use easily observed variables as proxies for the underlying physical driving forces and - if driven by AGCM in an offline mode - will not account for potentially important feedbacks between soil moisture and 
AGCM-predicted atmospheric variables (lack of feedback is not an issue when using observed atmospheric variables in an operational setting).

Given the difficulties with current LSSs in making consistent predictions of soil moisture change, we believe that the operational PE approach has equal merit as an alternative and complementary method for assessing possible future changes in soil moisture. The Thornthwaite equation and related methods have a long history and are familiar to agricultural planners. The development of a PE model that can emulate the sensitivities of runoff and evapotranspiration to available soil moisture as found in different AGCM-LSSs would be useful in evaluating the robustness of simulated soil moisture changes in particular regions, and could be readily coupled to a variety of crop-yield models.

Acknowledgements We are grateful for the helpful comments of two anonymous reviewers. We are also thankful to Anne Henderson-Sellers for her suggestions. This research was supported by NSERC (Canada) grant 1413-02.

\section{References}

Alley WM (1984) The Palmer Drought Severity Index: limitations and assumptions. J Clim Appl Meteorol 23:1100-1109

Atherton BC, Brown LC, Fausey NR, Tornes L, Gehring RM, Steiger JR, Hall GS, Patterson JM, Prenger JJ, Brate AM, Zimmerman TL (1998) Development of a comprehensive agricultural water management guide for Ohio. In: Brown LC (ed) 7th international drainage symposium. St. Joseph, MI, ASAE, 7

Bagnoud N, Pitman AJ, McAvaney B, Holbrook NJ (2005) The contribution of the land surface energy balance complexity to differences in means, variances and extremes using the AMIP-II methodology. Clim Dyn 25:171-188

Baumgartner A, Reichel E (1975) The world water balance: mean annual global, continental and maritime precipitation, evaporation and runoff. Elsevier, Amsterdam

Bell J, Duffy P, Covey C, Sloan L (2000) Comparison of temperature variability in observations and sixteen climate model simulations. Geophys Res Lett 27:261-264

Boer GJ, Flato G, Ramsden D (2000) A transient climate change simulation with greenhouse gas and aerosol forcing: projected climate to the twenty-first century. Clim Dyn 16:427-450

Brabson BB, Lister DH, Jones PD, Palutikof JP (2005) Soil moisture and predicted spells of extreme temperatures in Britain. J Geophys Res 110:D05104

Brumbelow K, Georgakakos A (2001) An assessment of irrigation needs and crop yield for the United States under potential climate changes. J Geophys Res D106:27383-27405

Budyko MI (1956) Heat balance of the earth's surface. Gidrometeoisdat, Leningrad

Chen F, Mitchell K, Schaake JC, Xue Y, Pan H-L, Koren VI, Duan QY, Ek M, Betts AK (1996) Modeling of land surface evaporation by four schemes and comparison with FIFE observations. J Geophys Res 101D:7251-7268

Chen TH, Henderson-Sellers A, Milly PCD, Pitman AJ, Beljaars ACM, Abramopoulos F, Boone A, Chang S, Chen F, Dai Y, Desborough CE, Dickinson RE, Dümenil L, Ek M, Garratt JR, Gedney N, Gusev YM, Kim J, Koster RD, Kowalczyk E, Laval K, Lean J, Lettenmaier DP, Liang X, Mengelkamp T-H, Mahfouf J-F, Mitchell K, Nasonova O, Noilhan J, Polcher J, Robock A, Rosenzweig C, Schaake JC, Schlosser CA, Schulz J-P, Shao Y, Shmakin AB, Verseghy DL, Wetzel P, Wood EF, Xue Y, Yang Z-L, Zeng Q (1997) Cabauw experimental results from the Project for Intercomparison of Land-Surface Parameterization Schemes (PILPS). J Climate 10:1194-1215

Cox PM, Betts RA, Bunton CB, Essery RLH, Rowntree PR, Smith J (1999) The impact of new land surface physics on the GCM simulation of climate and climate sensitivity. Clim Dyn 15:183-203

Crossley JF, Polcher J, Cox PM, Gedney N, Planton S (2000) Uncertainties linked to land surface processes in climate change simulations. Clim Dyn 16:949-961

Desborough CE (1999) Surface energy balance complexity in GCM land surface models. Clim Dyn 15:389-403

Desborough CE, Pitman AJ, Irannejad P (1996) Analysis of the relationship between bare soil evaporation and soil moisture simulated by 13 land surface schemes for a simple non-vegetated site. Glob Planet Change 13:47-56 
Dickinson RE, Henderson-Sellers A, Kennedy PJ (1993) Biosphere-Atmosphere Transfer Scheme (BATS) Version 1e as coupled to the NCAR Community Climate Model, Tech. note TN-275+STR, NCAR Climate and Global Dynamics Division, Boulder, CO

Dirmeyer P (2001) An evaluation of the strength of land-atmosphere coupling. J Hydrometeorol 2:329-344

Dirmeyer PA (2004) Soil moisture - muddy prospects for a clear definition. GEWEX News 14:11-12

Dirmeyer PA, Dolman AJ, Sato N (1999) The pilot phase of the Global Soil Wetness Project. Bull Am Meteorol Soc 80:851-878

Dirmeyer PA, Zeng FJ, Ducharne A, Morrill JC, Koster RD (2000) The sensitivity of surface fluxes to soil water content in three land surface schemes. J Hydrometeorol 1:121-134

Dirmeyer P, Gao X, Oki T (2002) The Second Global Soil Wetness Project (GSWP-2). No. 37, IGPO Publication Series

Ducharne A, Laval K (2000) Influence of the realistic description of soil water-holding capacity of the global water cycle in a GCM. J Climate 13:4393-4413

Ducharne A, Laval K, Polcher J (1998) Sensitivity of the hydrological cycle to the parameterization of soil hydrology in a GCM. Clim Dyn 14:307-327

Durre I, Wallace JM, Lettenmaier DP (2000) Dependence of extreme daily maximum temperatures on antecedent soil moisture in the contiguous United States during summer. J Climate 13:2641-2651

Emori S, Nozawa T, A, Abi-Ouchi, Numaguti A, Kimoto M, Nakajima T (1999) Coupled ocean-atmosphere model experiments of future climate change with an explicit representation of sulfate aerosol scattering. J Meteorol Soc Jpn 77:1299-1307

Feddema JJ (1999) Future African water resources: interactions between soil degradation and global warming. Clim Change 42:561-596

Feddema JJ, Mather JR (1992) Hydrological impacts of global warming over the United States. In: Majumdar SK, Kalkstein LS, Yarnal BM, Miller EW, Rosenfeld LM (eds), Global climate change: implications, challenges and mitigation measures. Pennsylvania Academy of Sciences, Easton, PA, pp 50-62

Federer CA, Vörösmarty C, Fekete B (1996) Intercomparison of methods for calculating potential evapotranspiration in regional and global water balance models. Water Resour Res 32:2315-2321

Gedney N, Cox PM, Douville H, Polcher J, Valdes PJ (2000) Characterizing GCM land surface schemes to understand their responses to climate change. J Climate 13:3066-3079

Georgakakos KP, Smith DE (2001) Soil moisture tendencies into the next century for the conterminous United States. J Geophys Res D106:27367-27382

Gifford RM, Farquhar GD, Roderick ML, Nicholls N (2004) Workshop summary. In: Gifford RM (ed) Workshop on pan evaporation: an example of the detection and attribution of climate change variables. Canberra, Australia, November 22-23, Australian Academy of Science, pp 4-19

Gregory JM, Mitchell JFB, Brady AJ (1997) Summer drought in northern midlatitudes in a time-dependent $\mathrm{CO}_{2}$ climate experiment. J Climate 10:662-686

Harvey LDD (2000) Global warming: the hard science. Prentice Hall, Harlow, Essex

Harvey LDD (2004) Characterizing the annual-mean climatic effect of anthropogenic CO2 and aerosol emissions in eight coupled atmosphere-ocean GCMs. Clim Dyn 23:569-599

Heim Jr. RR (2002) A review of twentieth-century drought indices used in the United States. Bull Am Meteorol Soc 83:1149-1165

Henderson-Sellers A (1996) Soil moisture simulation: Achievements of the RICE and PILPS intercomparison workshop and future directions. Global Planet Change 13:99-115

Henderson-Sellers A, Yang Z-L, Dickinson RE (1993) The project for intercomparison of land-surface parameterization schemes. Bull Am Meteorol Soc 74:1335-1349

Henderson-Sellers A, McGuffie K, Gross C (1995a) Sensitivity of global climate model simulations to increased stomatal resistance and CO2 increases. J Climate 8:1738-1756

Henderson-Sellers A, Pitman AJ, Love PK, Irannejad P, Chen TH (1995b) The project for intercomparison of land surface parameterization schemes (PILPS): phases 2 and 3. Bull Am Meteorol Soc 76:489-502

Henderson-Sellers A, McGuffie K, Pitman AJ (1996) The Project for Intercomparison of Land-Surface Parameterization Schemes (PILPS): 1992 to 1995. Clim Dyn 12:849-859

Henderson-Sellers A, Pitman AJ, Irannejad P, McGuffie K (2002) Land-surface simulations improve atmospheric modeling. Eos Trans Am Geophys Union 83:145-152

Henderson-Sellers A, Irannejad P, McGuffie K, Pitman AJ (2003a) Predicting land-surface climates - better skill or moving targets? Geophys Res Lett 30:1777

Henderson-Sellers A, Irannejad P, Sharmeen S, Phillips TJ, McGuffie K, Zhang H (2003b) Evaluating GEWEX CSEs' simulated land-surface water budget components. GEWEX News 13:3-6,19

Houghton JT, Filho LGM, Callander BA, Harris N, Kattenberg A, Maskell K (eds) (1996) Climate change 1995: the science of climate change. Cambridge University Press 
Huang J, van den Dool HM, Georgakakos KP (1996) Analysis of model-calculated soil moisture over the United States (1931-1993) and applications for long-range temperature forecasts. J Climate 9:1350-1362

Irannejad P, Henderson-Sellers A, Phillips TJ, McGuffie K (2001) Sensitivity of climate simulations to landsurface complexity: Beginning AMIP II Diagnostic Subproject 12. In: 12th symposium on global change and climate variations. Albuquerque, New Mexico, American Meteorological Society, pp 193-196

Irannejad P, Henderson-Sellers A, Sharmeen S (2003) Importance of land-surface parameterization for latent heat simulation in global atmospheric models. Geophys Res Lett 30:1904

Jensen ME (ed) (1973) Consumption use of water and irrigation water requirements. American Society of Civil Engineers, New York

Kattenberg A, Giorgi F, Grassl H, Meehl GA, Mitchell JFB, Stouffer RJ, Tokioka T, Weaver AJ, Wigley TML (1996) Climate models - projections of future climate. In: Houghton JT, Filho LGM, Callander BA et al. (eds) Climate change 1995: the science of climate change. Cambridge University Press, Cambridge, pp 285-357

Koster RD, Milly PCD (1997) The interplay between transpiration and runoff formulations in land surface schemes used with atmospheric models. J Climate 10:1578-1591

Koster RD, Dirmeyer PA, Hahmann AN, Ijpelaar R, Tyahla L, Cox P, Suarez MJ (2002) Comparing the degree of land-atmosphere interaction in four atmospheric general circulation models. J Hydrometeorol 2:363-375

Koster RD, Dirmeyer P, Guo Z, Bonan GB, Chan E, Cox P, Gordon CT, Kanae S, Kowalczyk E, Lawrence D, Liu P, Lu C-H, Malyshev S, McAvaney B, Mitchell K, Mocko D, Oki T, Oleson K, Pitman A, Sud YC, Taylor CM, Verseghy DL, Vasic R, Xue Y, Yamada T (2004) Regions of strong coupling between soil moisture and precipitation. Science 305:1138-1140

Leplastrier M, Pitman AJ, Gupta H, Xia Y (2002) Exploring the relationship between complexity and performance in a land surface model using the multicriteria method. J Geophys Res D107:4443

Lettau HH (1969) Evapotranspiration climatonomy. I. A new approach to numerical prediction of monthly evapotranspiration, runoff and soil moisture storage. Mon Weather Rev 97:691-699

Liang X, Wood EF, Lettenmaier DP, Lohmann D, Boone A, Chang S, Chen F, Dai Y, Desborough CE, Dickinson RE, Duan QY, Ek M, Gusev YM, Habets F, Irannejad P, Koster RD, Mitchell KE, Nasonova ON, Noilhan J, Schaake JC, Schlosser CA, Shao Y, Shmakin AB, Verseghy DL, Warrach K, Wetzel P, Xue Y, Yang Z-L, Zeng Q (1998) The Project for Intercomparison of Land-Surface Parameterization Schemes (PILPS) phase 2(c) Red-Arkansas River basin experiment: 2. Spatial and temporal analysis of energy fluxes. Global Planet Change 19:137-159

Lockwood JG (1999) Is potential evapotranspiration and its relationship with actual evapotranspiration sensitive to elevated atmospheric CO2 levels? Clim Change 41:193-212

Lynch-Stieglitz M (1994) The development and validation of a simple snow model for the GISS GCM. J Climate 7:1842-1855

Mahfouf J-F, Ciret C, Ducharne A, Irannejad P, Noilhan J, Shao Y, Thornton P, Xue Y, Yang Z-L (1996) Analysis of results from the PILPS-RICE workshop part III: transpiration. Global Planet Change 13:73-88

Manabe S (1969) Climate and the ocean circulation: I. The atmospheric circulation and the hydrology of the Earth's surface. Mon Weather Rev 97:739-774

Mather JR (1962) Average climatic water balance data of the continents: part 1, Africa. Publ Climatol 15(2), Laboratory of Climatology, Centerton, NJ

Mather JR (1963a) Average climatic water balance data of the continents: part 2, Asia (excluding U.S.S.R.). Publ Climatol 16(1), Laboratory of Climatology, Centerton, NJ

Mather JR (1963b) Average climatic water balance data of the continents: part 3, U.S.S.R. Publ Climatol 16(2), Laboratory of Climatology, Centerton, NJ

Mather JR (1963c) Average climatic water balance data of the continents: part 4, Australia, New Zealand, and Oceania. Publ Climatol 16(3), Laboratory of Climatology, Centerton, NJ

Mather JR (1964a) Average climatic water balance data of the continents: part 5, Europe. Publ Climatol 17(1), Laboratory of Climatology, Centerton, NJ

Mather JR (1964b) Average climatic water balance data of the continents: part 6, North America (excluding United States). Publ Climatol 17(2), Laboratory of Climatology, Centerton, NJ

Mather JR (1964c) Average climatic water balance data of the continents: part 7, United States. Publ Climatol 17(3), Laboratory of Climatology, Centerton, NJ

Mather JR (1965) Average climatic water balance data of the continents: part 8, South America. Publ Climatol 18(2), Laboratory of Climatology, Centerton, NJ

McGuiness JL, Bordne EF (1972) A comparison of lysimeter-derived potential evapotranspiration with computed values. Tech Bull 1452. USDA Agricultural Research Service, Washington DC

Mearns LO, Easterling W, Hays C, Marx D (2001) Comparison of agricultural impacts of climate change calculated from high and low resolution climate change scenarios: part I. The uncertainty due to spatial scale. Clim Change 51:131-172 
Milly PCD (1992) Potential evaporation and soil moisture in general circulation models. J Climate 5:209-226

Milly PCD (1994a) Climate, interseasonal storage of soil water, and the annual water balance. Adv Water Resour 17:19-24

Milly PCD (1994b) Climate, soil water storage, and the average annual water balance. Water Resour Res 30:2143-2156

Mintz Y, Serafini YV (1984) Global fields of monthly normal soil moisture as derived from observed precipitation and an estimated evapotranspiration. Final scientific report under NASA grant NAS 5-26 part V, University of Maryland Department of Meteorology, College Park, MD

Mintz Y, Serafini YV (1992) A global monthly climatology of soil moisture and water balance. Clim Dyn 8:13-27

Mintz Y, Walker GK (1993) Global fields of soil moisture and land surface evapotranspiration derived from observed precipitation and surface air temperature. J Appl Meteorol 32:1305-1334

Monteith JL (1965) Evaporation and environment. Symp Soc Exp Biol 19:205-234

Nazarenko L, Menon S (2005) Varying trends in surface energy fluxes and associated climate between 1960 and 2002 based on transient climate simulations. Geophys Res Lett 32:L22704

Nicholson SE, Kim J, Ba MB, Lare AR (1997) The mean surface water balance over Africa and its variability. J Climate 10:2981-3002

Palmer WC (1965) Meteorological drought. Research paper no. 45, U.S. Weather Bureau, Washington DC

Pelton WL, King KM, Tanner CB (1960) An evaluation of the Thornthwaite and mean temperature methods for determining potential evapotranspiration. Agron J 52:387-395

Penman HL (1948) Natural evaporation from open water, bare soil and grass. Proc R Soc Lond A193:120-145

Pitman AJ, Henderson-Sellers A, Abramopoulos F, Avissar R, Bonan GB, Boone A, Cogley JG, Dickinson RE, Ek M, Entekhabi D, Famiglietti J, Garrat JR, Frech M, Hahmann AN, Koster RD, Kowalczyk E, Laval K, Lean L, Lee TJ, Lettenmaier DP, Liang X, Mahfouf J-F, Mahrt L, Milly C, Mitchell K, de Noblet N, Noilhan J, Pan H, Pielke R, Robock A, Rosenzweig C, Running SW, Schlosser CA, Scott R, Suarez MJ, Thompson SL, Verseghy DL, Wetzel P, Wood EF, Xue Y, Yang Z-L, Zang L (1993) Results from the Off-line Control Simulation Phase of the Project for Intercomparison of Land-Surface Parameterisation Schemes (PILPS). IGPO Publication Series Tech. Note 7, GEWEX

Pitman AJ, Henderson-Sellers A (1995) Simulating the diurnal temperature range: Results from Phase 1(a) of the Project of Intercomparison of Land-Surface Parameterization Schemes (PILPS). Atmos Res 37: $229-245$

Pitman AJ, Henderson-Sellers A (1998) Recent progress and results from the Project for the Intercomparison of Land-Surface Parameterization Schemes. J Hydrol 212-213:128-135

Pitman AJ, Henderson-Sellers A, Desborough CE, Yang Z-L, Abramopoulos F, Boone A, Dickinson RE, Gedney N, Koster RD, Kowalczyk E, Lettenmaier DP, Liang X, Mahfouf J-F, Noilhan J, Polcher J, Qu W, Robock A, Rosenzweig C, Schlosser CA, Shmakin AB, Smith J, Suarez MJ, Verseghy DL, Wetzel P, Wood EF, Xue Y (1999a) Key results and implications from phase 1(c) of the Project for Intercomparison of Land-Surface Parameterization Schemes. Clim Dyn 15:673-684

Pitman AJ, Slater AG, Desborough CE, Zhao M (1999b) Uncertainty in the simulation of runoff due to the parameterization of frozen soil moisture using the GSWP methodology. J Geophys Res 104D: $16879-16888$

Pitman AJ, McAvaney BJ, Bagnoud N, Cheminat B (2004) Are inter-model differences in AMIP-II near surface air temperature means and extremes explained by land surface energy balance complexity? Geophys Res Lett 31:L05205

Polcher J, Laval K, Dümenil L, Lean J, Rowntree PR (1996) Comparing three land surface schemes used in general circulation models. J Hydrol 180:373-394

Priestly CHB, Taylor RH (1972) On the assessment of surface heat flux evaporation using large-scale parameters. Mon Weather Rev 100:81-92

Qu W, Henderson-Sellers A, Pitman AJ, Abramopoulos TCF, Boone A, Chang S, Chen F, Dai Y, Dickinson RE, Dümenil L, Ek M, Gedney N, Gusev YM, Kim J, Koster RD, Kowalczyk E, Lean J, Lettenmaier DP, Liang X, Mahfouf J-F, Mengelkamp H-T, Mitchell K, Nasonova O, Noilhan J, Robock A, Rosenzweig C, Schlosser CA, Schulz J-P, Shmakin AB, Verseghy DL, Wetzel P, Wood EF, Yang Z-L, Zeng Q (1998) Sensitivity of latent heat flux from PILPS land-surface schemes to perturbations of surface air temperature. J Atmos Sci 55:1909-1927

Ramirez JA, Hobbins MT (2005) Observational evidence of the complementary relationship in regional evaporation lends strong support for Bouchet's hypothesis. Geophys Res Lett 32:L15401

Rind D, Goldberg R, Hansen J, Rosenzweig C, Ruedy R (1990) Potential evapotranspiration and the likelihood of future drought. J Geophys Res 95D:9983-10004

Roads JO, Chen SC, Guetter AK, Georgakakos KP (1994) Large-scale aspects of the United States hydrologic cycle. Bull Am Meteorol Soc 75:1589-1610 
Robock A, Vinnikov KY, Schlosser CA, Speranskaya NA, Xue Y (1995) Use of midlatitude soil moisture and meteorological observations to validate soil moisture simulations with biosphere and bucket models. J Climate 8:15-35

Robock A, Vinnikov KY, Schlosser CA, Speranskaya NA, Xue Y (1998) Evaluation of the AMIP soil moisture simulations. Glob Planet Change 19:181-208

Roderick ML, Farquhar GD (2002) The cause of decreased pan evaporation over the past 50 years. Science 298:1410-1411

Schaake JC, Koren VI, Duan QY, Mitchell K, Chen F (1996) Simple water balance model for estimating runoff at different spatial and temporal scales. J Geophys Res 101D:7461-7475

Sellers PJ, Shuttleworth WJ, Dorman JL, Dalcher A, Roberts JA (1989) Calibrating the simple biosphere model for amazonian tropical forest using field and remote sensing data, part I: average calibration with field data. J Appl Meteorol 28:727-759

Sellers PJ, Randall DA, Collatz GJ, Berry JA, Field CB, Dazlich DA, Zhang C, Collelo GD, Bounoua L (1996) A revised land surface parameterization ( $\mathrm{SiB} 2)$ for atmospheric GCMs, part I: model formulation. J Climate 9:676-705

Sellers PJ, Dickinson RE, Randall DA, Betts AK, Hall FG, Berry JA, Collatz GJ, Denning AS, Mooney HA, Nobre CA, Sato N, Field CB, Henderson-Sellers A (1997) Modeling the exchanges of energy, water and carbon between continents and the atmosphere. Science 275:502-509

Shao Y, Henderson-Sellers A (1996) Modeling soil moisture: a project for intercomparison of land surface parameterization schemes phase 2(b). J Geophys Res 101D:7227-7250

Smith SJ, Pitcher H, Wigley TML (2005) Future sulfur dioxide emissions. Clim Change 73:267-318

Srinivasan G, Robock A, Entin JK, Luo L, Vinnikov KY, Viterbo P (2000) Soil moisture simulations in revised AMIP models. J Geophys Res 105D:26635-26644

Strahler AN, Strahler AH (1978) Modern physical geography. Wiley, New York

Thornthwaite CW (1948) An approach toward a rational classification of climate. Geogr Rev 38:55-89

Thornthwaite CW (1954) A re-examination of the concepts and measurement of potential evapotranspiration. In: Mather JR (ed) The measurement of potential evapotranspiration. Publ Climatol 7(1). Laboratory of Climatology, Centerton, NJ

Timbal B, Henderson-Sellers A (1998) Intercomparison of land-surface parameterizations coupled to a limited area forecast model. Glob Planet Change 19:247-260

Varis O, Kajander T, Lemmelä R (2004) Climate and water: from climate models to water resources management and vice versa. Clim Change 66:321-344

Verseghy DL (1991) CLASS - a Canadian land surface scheme for GCMs: I. Soil model. Int J Climatol $11: 111-133$

Verseghy DL, McFarlane NA, Lazare M (1993) CLASS - a Canadian land surface scheme for GCMs: II. Vegetation model and coupled runs. Int J Climatol 13:347-370

Vinnikov KY, Yeserkepova IB (1991) Soil moisture: empirical data and model results. J Climate 4:66-79

Waltman WJ, Ciolkosz EJ, Mausbach MJ, Svoboda MD, Miller DA, Kolb PJ (1997) Soil climate regimes of Pennsylvania, bulletin no. 873. Pennsylvania State University Agricultural Experiment Station, University Park, PA

Wild M, Gilgen H, Roesch A, Ohmura A, Long CN, Dutton EG, Forgan B, Kallis A, Russak V, Tsvetkov A (2005) From dimming to brightening: decadal changes in solar radiation at Earth's surface. Science 308:847-850

Willmott CJ, Mather JR, Rowe CM (1981a) Average monthly and annual surface air temperature and precipitation data for the world, Part 1: the eastern hemisphere. Publ Climatol 34(1), Laboratory of Climatology, Centerton, NJ

Willmott CJ, Mather JR, Rowe CM (1981b) Average monthly and annual surface air temperature and precipitation data for the world, Part 2: the western hemisphere. Publ Climatol 34(2), Laboratory of Climatology, Centerton, NJ

Willmott CJ, Mather JR, Mintz Y (1985) Climatology of the terrestrial seasonal water cycle. J Climatol 5:589-606

Wu W, Dickinson RE (2005) Warm-season rainfall variability over the US Great Plains and its correlation with evapotranspiration in a climate simulation. Geophys Res Lett 32:L17402

Yang Z-L, Dickinson RE, Henderson-Sellers A, Pitman AJ (1995) Preliminary study of spin-up processes in soil-vegetation-atmosphere transfer schemes with the first stage data of PILPS phase 1(a). J Geophys Res 100D:16553-16578

Zhang H (2004) Analyzing the potential impacts of soil moisture on the observed and model-simulated Australian surface temperature variations. J Climate 17:4190-4212

Zhang H, Henderson-Sellers A, Pitman AJ, McGregor JL, Desborough CE, Katzfey JJ (2001) Limited-area model sensitivity to the complexity of representation of the land surface energy balance. J Climate 14:3965-3986 